\title{
O acesso à justiça e nova sistemática da execução de sentença introduzida pela Lei №. 11.232/2005
}

\author{
Cristiane Maria Haggi Favero ${ }^{1}$
}

\begin{abstract}
Resumo
$\mathrm{O}$ acesso à justiça, requisito fundamental do sistema jurídico moderno, é alcançado pela prestação plena e eficaz da tutela jurisdicional. Na busca da celeridade e efetividade processual, percebe-se que a execução da sentença é um dos pontos mais críticos do processo civil vigente, pois muitas são as dificuldades encontradas pelo vencedor da causa, o qual é obrigado a instaurar um novo processo para que possa ser efetivado o comando judicial. Deste modo, a Lei no. 11.232/2005, tem por finalidade modernizar a execução da sentença, pondo fim à dicotomia até então existente entre processo de conhecimento e de execução, passando a adotar o que a doutrina denominou de 'processo sincrético', ou seja, a integração das atividades cognitiva e executiva, propiciando a efetividade da tutela jurisdicional.
\end{abstract}

Palavras-Chave: Acesso à justiça; Celeridade e efetividade Processual; Execução de sentença; Lei no. 11.232/2005

\section{Introdução}

O presente trabalho visa analisar o acesso à justiça sob a ótica das alterações ocorridas no Código de Processo Civil quanto à execução de sentença com a promulgação da Lei no. $11.232^{2}$, de 22 de dezembro de 2005.

A noção de acesso à justiça evoluiu paralelamente à passagem da concepção liberal para a concepção social do Estado moderno.

Assim, se de início bastava a declaração formal dos direitos humanos, limitando-se a ordem constitucional a criar mecanismos de acesso à justiça, atualmente, a Constituição, refletindo a consciência social dominante, não mais se contenta em somente declarar o direito ao acesso à justiça, mas tem por escopo principalmente garantí-lo, tornandoo realmente acessível a todos e efetivo ${ }^{3}$.

Especialista em Direito do Estado - Direito Constitucional pela Universidade Estadual de Londrina 2 A Lei no. 11.232/2005 foi publicada no DOU em 23/12/2005, e segundo disposto em seu artigo 8으 ela entrará em vigor 6 (seis) meses após a data de sua publicação.

3 CAPPELLETTI, Mauro; GARTH Bryant. Acesso à Justiça. trad. Ellen Gracie Northfleet. Porto Alegre: Sergio Antonio Fabris Editor, 1988. p. 9/13. 
Hoje em dia, portanto, não é possível pensar-se em um sistema jurídico moderno e igualitário, sem a garantia do acesso à justiça, considerada um requisito fundamental, " $O$ mais básico dos direitos humanos"".

Sendo o acesso à justiça um direito fundamental do cidadão, assegurado Constitucionalmente, faz-se necessário tomar as providências para que ele seja o máximo eficaz possível.

O processo, como instrumento de atuação de uma das principais garantias constitucionais - a tutela jurisdicional - deve, pois, ser organizado, entendido e aplicado como instrumento de efetivação do acesso à justiça, assegurando a todos o pleno acesso à tutela jurisdicional.

Não basta, portanto, a existência formal da garantia do acesso à justiça, sendo imprescindível que a tutela jurisdicional a ser prestada seja realmente plena e efetiva.

Segundo Wilges Bruscato ${ }^{5}$ "poderia se dizer que a efetividade do processo é a manifestação do direito processual ideal, dotado de um conjunto especial de medidas que visa garantir concretude ao direito material perseguido".

Atualmente, a efetividade também tem relação direta com a celeridade processual. Nesse sentido Donaldo Armelin ${ }^{6}$ preceitua que:

\begin{abstract}
a efetividade do processo está umbilicalmente vinculada a sua rapidez e celeridade em propiciar uma prestação de tutela jurisdicional eficaz. A morosidade nessa prestação sempre foi uma questão a desafiar a argucia e o talento dos cientistas do processo e dos legisladores.
\end{abstract}

Diante desta necessidade de se atrelar o acesso à justiça a prestação de uma tutela jurisdicional além de justa, realmente efetiva, percebe-se que um dos pontos mais críticos do processo civil brasileiro está na execução da sentença.

Como bem ponderado por Athos Gusmão Carneiro ${ }^{7}$ "A execução permanece o 'calcanhar de Aquiles' do processo. Nada mais difícil, com freqüência, do que impor no 'mundo dos fatos' os preceitos abstratamente formulados no 'mundo do direito'."

\footnotetext{
Expressão utilizada por Mauro Cappelletti e Bryant Garth, op. cit., p. 12.

BRUSCATO, Wilges. Efetividade do Processo de Execução, Repro 129, ano 30, nov./2005, p. 10.

ARMELIN, Donaldo apud BRUSCATO. op. cit. p. 11.

CARNEIRO, Athos Gusmão. Nova Execução. Aonde vamos? Vamos melhorar. Repro 123, Ano 30, Maio/2005. p. 116.
} 
Em decorrência dos problemas enfrentados pelo processo de execução na sua efetivação, é que se tornam necessárias alterações que visam nada mais do que adequá-lo a realidade e necessidade de um processo justo, eficaz e efetivo.

Portanto, tem por escopo o presente estudo analisar as alterações introduzidas na execução de sentença pela Lei no 11.232, de 22 de dezembro de 2005, em busca da garantia constitucional do efetivo acesso à justiça.

\section{Significado da expressão: "acesso à justiça”}

Cristaliza-se no âmbito do moderno Direito Constitucional a idéia de que o acesso à justiça pelo cidadão se constitui um direito fundamental a ser protegido pelo Estado.

No ordenamento jurídico pátrio, o direito ao acesso à justiça está inserido na Constituição Federal, em seu artigo 5으, inciso XXXV, denominado de princípio da inafastabilidade do controle jurisdicional, também conhecido como princípio da proteção judiciária, e preceitua que "A lei não excluirá da apreciação do Poder Judiciário lesão ou ameaça a direito".

Ocorre que a expressão "acesso à justiça" é mais ampla do que o acesso ao Poder Judiciário, e por esta razão, é reconhecidamente de difícil definição na doutrina.

Cappelletti e Bryant Garth ${ }^{8}$ registram que a expressão "acesso à justiça" serve para determinar duas finalidades básicas do sistema jurídico, o sistema pelo qual as pessoas podem reivindicar seus direitos e/ou resolver seus litígios sob os auspícios do Estado. Primeiro, o sistema deve ser igualmente acessível a todos; segundo, ele deve produzir resultados que sejam individualmente e socialmente justos.

Segundo Horácio W. Rodrigues ${ }^{9}$, frente à vagueza do termo acesso à justiça, que a ele são atribuídos pela doutrina diferentes sentidos, sendo eles fundamentalmente dois: o primeiro, atribuindo ao significante justiça o mesmo sentido e conteúdo que o de Poder Judiciário, torna sinônimas as expressões acesso à Justiça e acesso ao Poder Judiciário; o segundo, partindo de uma concepção axiológica da expressão justiça, compreende o acesso

CAPPELLETTI; GARTH. op. cit., p. 08.

RODRIGUES, Horácio Wanderley. Acesso à Justiça no Direito Processual Brasileiro. São Paulo: Editora Acadêmica, 1994, p. 28. 
a ela como o acesso a uma determinada ordem de valores e direitos fundamentais para o ser humano. Conclui que por ser o último mais amplo engloba no seu significado o primeiro.

Para J. E. Carreira Alvim ${ }^{10}$ o acesso à justiça:

compreende o acesso aos órgãos encarregados de ministrá-la, instrumentalizados de acordo com a nossa geografia social, e também um sistema processual adequado à veiculação das demandas, com procedimentos compatíveis com a cultura nacional, bem assim com a representação (em juízo) a cargo das próprias partes, nas ações individuais, e de entes exponenciais, nas ações coletivas, com assistência judiciária aos necessitados, e um sistema recursal que não transforme o processo numa busca interminável de justiça, tornando o direito da parte mais um fato virtual do que uma realidade social.

Quando se fala em acesso à justiça, portanto, não se pode visualizar apenas o direito de acesso ao Poder Judiciário, pois se está a falar em algo muito mais amplo que é o acesso a "ordem jurídica justa"1", na feliz expressão de Kazuo Watanabe.

Importante esclarecer, ainda, que o acesso à justiça pode se dar por meio da tutela jurisdicional, de que se encarrega o Estado, ou através de meios alternativos, como a arbitragem, a mediação e a conciliação.

A tutela jurisdicional, segundo as lições de Cândido Rangel Dinamarco ${ }^{12}$ :

é o amparo, que, por obra dos juízes, o Estado ministra a quem tem razão num litígio deduzido em processo. [...] Receber tutela jurisdicional significa obter sensações felizes e favoráveis, propiciadas pelo Estado mediante o exercício da jurisdição.

A tutela jurisdicional tradicional, entretanto, não é a única forma de conduzir as pessoas à ordem jurídica justa, extinguindo conflitos e satisfazendo pretensões.

Como bem ponderado por Alexandre Freitas Câmara ${ }^{13}$ :

10 ALVIM, J. E. Carreira, Justiça: acesso e decesso, Jus Navigandi, Teresina, a. 7, n. 65, mai. 2003. Disponível em: <http://jus2.uol.com.br/doutrina/texto.asp?id=4078>.

11 Expressão de Kazuo Watanabe, "Acesso à justiça e sociedade moderna", in Ada Pellegrini Grinover, Cândido Rnangel Dinamarco e Kazuo Watanabe (coord.), Participação e processo, São Paulo: Revista dos Tribunais, 1988, p. 128.

12 DINAMARCO, Cândido Rangel, Instituições de direito processual civil, vol. I, 5ạ ed, São Paulo: Malheiros Editores, 2005, p. 123.

13 CÂMARA, Alexandre Freitas, $\mathrm{O}$ acesso à justiça no plano dos direitos humanos in Acesso à Justiça, organizador Raphael Augusto Sofiati de Queiroz. Rio de Janeiro: Lúmen Júris, p. 06. 
a utilização dos meios alternativos de composição de conflitos é interessante não só para as partes envolvidas no conflito, que podem ter a resolução do mesmo ditada por um especialista na matéria que goze de sua confiança (o árbitro), através de um procedimento célere e sigiloso, ou que podem alcançar elas mesmas a solução do conflito, com a ajuda de alguém com treinamento específico para auxiliar os interessados a obter uma composição que agrade a todos (o mediador); mas também é interessante para o Estado, que terá um número de conflitos para solucionar tanto menor quanto maior seja o número de conflitos submetidos aos meios alternativos de resolução.

Vale esclarecer, entretanto, que somente a jurisdição, por se tratar de função Estatal, possui como características a imperatividade e a inevitabilidade ${ }^{14}$, ausentes nos outros meios de solução dos conflitos.

Cândido Rangel Dinamarco pondera, ainda, que "somente a jurisdição tem entre seus objetivos o de dar efetividade ao ordenamento jurídico substancial, o que obviamente está fora de cogitação nos chamados meios alternativos.

Esclarece, entretanto, o citado autor, que o que há de substancialmente relevante no exercício da jurisdição, também está presente nessas outras atividades, que é a busca de pacificação das pessoas e grupos mediante a eliminação de conflitos que os envolvam.

\section{As ondas renovatórias do acesso à justiça}

O acesso à justiça tem sido, pois, uma das maiores preocupações da atualidade, no sentido de importar-se com os alcances dos escopos jurídico, social e político do processo, conduzindo à realidade de estudos exaustivos sobre o tema para desvendar os reais obstáculos à sua concretização e possibilitar a adoção de mecanismos capazes de assegurar a sua efetividade.

Doutrinariamente ficaram conhecidas como as três ondas renovatórias em prol do acesso efetivo à justiça, preconizadas na obra "Acesso à Justiça", de Mauro Cappelletti e Bryan Garth, que nada mais são do que a identificação dos principais obstáculos ao acesso à justiça.

A primeira onda para o acesso à ordem jurídica justa é a "assistência judiciária para os pobres" ${ }^{15}$ que nada mais é do que vencer as barreiras impostas aos cidadãos desprovidos

14 Inevitabilidade, segundo Cândido Rangel Dinamarco, "é a relação de autoridade e sujeição, existente entre o Estado e os particulares, é o fator legitimante da inevitabilidade do poder estatal e do seu exercício". (in Instituições de direito processual civil, vol. I, 5ạ ed, São Paulo: Malheiros Editores, 2005, p. 332). 
de recursos financeiros para litigar em juízo, seja pela falta de condições para contratar profissional habilitado, ou mesmo para suportar o alto custo das despesas com custas durante a trajetória processual.

Como ponderado por Alexandre Freitas Câmara ${ }^{16}$ :

de nada adiantaria afirmar-se que todos são sujeitos de direitos se não se criam as condições necessárias para que todos possam ver seus direitos atuados concretamente pelo Judiciário. O fato de o serviço judiciário ser pago sempre foi um obstáculo a que as camadas mais carentes da sociedade tivessem negado o acesso à tutela jurisdicional.

No ordenamento jurídico brasileiro a Lei no 1.060/50 dispõe sobre a assistência judiciária, sendo relevante destacar que na atualidade, nos termos do artigo 50, LXXIV $^{17}$, da Constituição Federal de 1988, tal conceito sofreu mudanças no sentido de abranger não apenas o patrocínio gratuito por profissional e a dispensa de pagamento de despesas processuais, mas também a assistência prestada na fase pré-processual ${ }^{18}$.

Também como forma de vencer a barreira de natureza econômica, a Carta Magna instituiu a Defensoria Pública, artigo $134^{19}$, instituição considerada essencial à função jurisdicional do Estado, "incumbindo-Ihe a orientação jurídica e a defesa, em todos os graus, dos necessitados, na forma do art. 5o, LXXIV", e organizada pela Lei Complementar Federal ก‥ $80 / 94$.

A segunda onda protetiva do efetivo acesso à justiça refere-se ao sistema processual e a representação dos interesses difusos.

15 Expressão utilizada por J. E. Carreira Alvim em: Justiça: acesso e decesso, Jus Navigandi, Teresina, a.

7, n. 65, mai. 2003. Disponível em: http://jus2.uol.com.br/doutrina/texto.asp?id=4078

16 CÂMARA, Alexandre Freitas. op. cit. , p. 03.

17 Art. 50, inciso LXXIV "o Estado prestará assistência jurídica integral e gratuita aos que comprovarem insuficiência de recursos".

18 Segundo Fabio Costa Soares "iniciando-se pela informação e tomada de consciência, passando pela orientação jurídica, encaminhamento aos órgãos competentes e culminando com a assistência judiciária prestada em juízo". In Acesso do Hipossuficiente à Justiça. A Defensoria Pública e a Tutela dos Interesses Coletivos Lato Sensu dos Necessitados.

19 “Art. 134 - A Defensoria Pública é instituição essencial à função jurisdicional do Estado, incumbindo-Ihe a orientação jurídica e a defesa, em todos os graus, dos necessitados, na forma do art. 5o, LXXIV", da Constituição da República de 1988. 
O sistema processual civil brasileiro, bem como o de diversos outros países, foi formado com o fim de permitir a resolução de conflitos interindividuais, os famosos conflitos entre “Caio e Tício" ${ }^{20}$, tão utilizados no próprio ensino do direito no Brasil.

Atualmente, na sociedade de massa, onde se busca a preservação de bens e valores que interessam a um grupo de pessoas, e não somente a pessoas individualmente consideradas, o processo civil individualista não se mostra mais perfeitamente adequado e efetivo para a satisfação da tutela jurisdicional, razão pela qual o legislador brasileiro tem buscado sistematizar um processo coletivo.

Diante da constatada incapacidade do processo civil tradicional, de cunho individualista, para servir de proteção aos interesses coletivos, seria necessário ocorrer mudanças na postura do processo civil, que de uma visão individualista, funde-se numa concepção social e coletiva, como forma de assegurar a realização dos direitos públicos e otimizar o acesso à justiça.

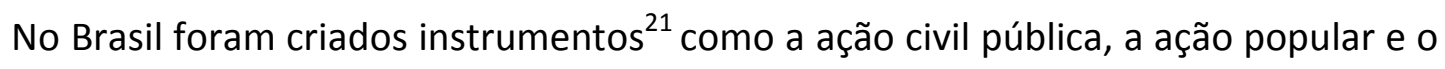
mandado de segurança coletivo são de extrema relevância para o alcance pleno do acesso à justiça.

Não é possível pensar-se em acesso à ordem jurídica justa se não houver meios de proteção ao meio ambiente, patrimônio histórico, consumidores, além de tantos outros interesses coletivos carentes de tutela por parte do Estado.

Por fim, passamos à análise da terceira onda renovatória, que é o "novo enfoque de acesso à justiça" ${ }^{22}$. Revela-se em múltiplas tentativas de obtenção de fins diversos, entre os quais estão os procedimentos mais acessíveis, simples e racionais, mais econômicos, eficientes e adequados a certos tipos de conflitos.

Este no novo enfoque de acesso à justiça tem alcance muito mais amplo, centrando sua atenção no conjunto geral de instituições e mecanismos, pessoas e procedimentos utilizados para processar e mesmo prevenir disputas nas sociedades modernas ${ }^{23}$.

\footnotetext{
20 CÂMARA, Alexandre Freitas. op. cit., p. 03.

21 Segundo Alexandre Freitas Câmara a proteção dos direitos metaindividuais "se conseguiu entre nós, através da criação mais rico instrumental de proteção de interesses difusos, coletivos, e individuais homogêneos de que se tem notícia no mundo". In $\mathrm{O}$ acesso à justiça no plano dos direitos humanos op. cit., p. 04.

22 Expressão utilizada por Mauro Cappelletti e Bryant Garth, op. cit, p. 08.

23 CAPPELLETTI, Mauro; GARTH Bryant, op. cit. p. 67/68.
} 
Essa onda encoraja a exploração de uma ampla variedade de reformas, incluindo alterações nas formas de procedimento, mudanças na estrutura dos tribunais ou criação de novos tribunais, o uso de pessoas leigas, como juízes e defensores, modificações no direito substantivo destinadas a evitar litígios ou facilitar sua solução, e a utilização de mecanismos privados ou informais de solução de litígios. Esse enfoque, em suma, não receia inovações radicais e compreensivas, que vão muito além da esfera de representação judicial. ${ }^{24}$

Parte-se do acesso à justiça, visto sob a ótica do consumidor da justiça, onde se faz presente a preocupação com a garantia de satisfação do jurisdicionado com a prestação da tutela jurisdicional, onde busca-se ampliar o acesso à justiça sob um novo enfoque, qual seja, o do consumidor de justiça.

Alexandre Freitas Câmara assevera que "a revolução que está por vir, e que será capaz de permitir o verdadeiro acesso à justiça, deverá ter os olhos postos no consumidor dos serviços processuais". 25

Por fim, salienta-se que nesta terceira onda a problemática, como bem ponderado pela professora Ada Pellegrini Grinover ${ }^{26}$, não discute somente um programa de reformas, mas, sobretudo, um método de pensamento, pois de nada valem as reformas se os operadores do direito não aplicarem no cotidiano jurídico de maneira que o acesso à justiça possa valer na acepção do termo, tornando-o efetivo e acessível.

\section{A execução de sentença}

O nosso diploma processual vigente é o Código de Processo Civil de 1973, que teve seu anteprojeto elaborado por Alfredo Buzaid, que era um dos maiores discípulos de Liebman no Brasil, sendo, pois, grande sua influência processo civil brasileiro.

O Código de Processo Civil caracterizava-se, na origem, por ter sido muito bem elaborado cientificamente, embora possuísse diversos problemas quanto à sua utilização prática $^{27}$.

24 Idem, p. 71.

$\mathrm{O}$ acesso à justiça no plano dos direitos, op. cit., p. 05.

26 GRINOVER, Ada Pellegrini. O Processo em evolução. Acesso a Justiça e o Código de Defesa doConsumidor. 2. ed. Rio de Janeiro: Forense Universitária, 1998, p. 116.

27 MARTINEZ, Maria Beatriz. O sistema de execução e as reformas do código de processo civil. Repro 128, Ano 30, outubro/2005, p. 129. 
Segundo Liebman, a execução de sentença devia ser considerada um processo autônomo perante o processo de conhecimento em que a sentença tivesse sido proferida.

Assim, o modelo adotado pelo Código de Processo Civil, elaborado com base na doutrina então dominante, tratava o processo de execução como um processo autônomo em relação ao processo de conhecimento condenatório.

Por conseguinte, após o longo contraditório no processo de conhecimento, quando finalmente obtida a prestação jurisdicional definitiva com o trânsito em julgado da sentença condenatória a parte não recebe de imediato o "bem da vida" que lhe foi reconhecido.

A sentença condenatória é título executivo, mas não se reveste de preponderante eficácia executiva, sendo que se o vencido não cumpre voluntariamente o dispositivo da sentença faz-se necessário um novo processo, que é o de execução.

Ocorre que, com o decorrer dos anos percebeu-se que este modelo de execução não mais atendia às reais necessidades da sociedade moderna, que clama por celeridade e efetividade na prestação da tutela jurisdicional.

\section{Motivos que ensejaram as reformas na execução de sentença}

Diante da necessidade da efetiva tutela jurisdicional através do processo e de sua instrumentalidade substancial, como forma de assegurar a realização da garantia constitucional de acesso à "ordem jurídica justa", a execução de sentença tem passado por relevantes mudanças no sentido de adequar os clássicos esquemas processuais à realidade social contemporânea.

As reformas setoriais efetivadas no Código de Processo Civil, foram uma iniciativa da Escola Nacional da Magistratura e do Instituto Brasileiro de Direito Processual.

Várias eram as críticas na doutrina tocante à dualidade do processo de conhecimento e de execução.

Alcalá - Zamora ${ }^{28}$ combateu o tecnicismo da dualidade, artificialmente criado no direito processual, entre 'processo de conhecimento' e 'processo de execução'.

Sustenta ser mais exato falar apenas em fase processual de conhecimento e de fase processual de execução, que de processo de uma e de outra classe. Isto porque "a unidade

28 CARNEIRO, op. cit., p. 117. 
da relação jurídica e da função processual se estende ao longo de todo o procedimento, em vez de romper-se em um dado momento" .

Athos Gusmão Carneiro ${ }^{29}$ defende que:

Com efeito, as teorias são importantes, mas não podem transformar-se em um embaraço a que se atenda as exigências naturais dos objetivos visados pelo processo, isso só por apego a tecnicismo formal. A velha tendência de restringir a jurisdição ao processo de conhecimento é hoje idéia do passado, de sorte que a verdade por todos aceita é a da completa e indispensável integração das atividades congnitivas e executivas.

Nesse sentido, Humberto Theodoro Junior ${ }^{30}$, ressalta que:

atual 'dicotomia' importa a paralisação da prestação jurisdicional logo após a sentença e a complicada instauração de um novo procedimento, para que o vencedor possa finalmente tentar impor ao vencido o comando soberano contido no decisório judicial. há, destarte, um longo intervalo entre a definição do direito subjetivo lesado e sua necessária restauração, isso por pura imposição do sistema procedimental, sem nenhum a justificativa quer de ordem lógica, quer teórica, quer de ordem prática.

Percebe-se, que a separação até então existente entre o processo de conhecimento e o de execução não mais atendia aos anseios do processo civil moderno.

Diante da situação existente, a Disciplina do processo de execução foi remodelada mediante reformas que buscavam principalmente o aumento da praticidade e da celeridade processual.

\section{Nova sistemática de execução de sentença introduzida pela Lei no 11.232/2005}

A Lei no 11.232/2005 tem como fundamento o anteprojeto de lei elaborado pelo Instituto de Direito Processual, da qual são signatários os Sr. Ministro Athos Gusmão Carneiro, o Sr. Ministro Sálvio de Figueiredo Teixeira, o Sr. Petrônio Calmon Filho e a Srạ. Ministra Fátima Nancy Andrighi. Originou-se o Projeto de Lei n.o 3.253/2004, que foi apresentado pelo Poder Executivo na Câmara dos Deputados em 29 de março de 2004, dentro do conjunto de propostas do Governo Federal para a Reforma do Poder Judiciário.

29 Ibidem. p. 117.

30 THEODORO JR., Humberto. Celeridade e efetividade da prestação jurisdicional. Insuficiência da reforma das leis processuais. Revista de Processo. São Paulo: Revista dos Tribunais - Repro 125, Ano 30, Julho/2005. 
Com a promulgação da Lei no 11.232/2005, publicada no Diário Oficial da União em 23 de dezembro de 2005, houve uma ruptura teórica, abandonando-se a tradicional lição de Liebman, com a consagração do fim do processo de execução autônomo das sentenças ${ }^{31}$, transformando-o numa etapa do processo de conhecimento.

Ressalta-se que a reforma introduzida pela Lei $\mathrm{n}$ ‥ 11.232/2005, vem completar a reforma iniciada em $2002^{32}$, que suprimiu o processo autônomo da execução de sentença para os casos de obrigação de fazer e não fazer.

Agora, acaba-se de vez com a execução de título judicial, introduzindo nova técnica de efetivação do julgado, sendo o cumprimento da sentença apenas uma fase processual. Percebe-se que as inovações são concentradas nas regras criadas para a execução para pagamento de quantia.

Observação importante a ser feita é que com a nova sistemática há alteração do próprio conceito de sentença, que antes era entendido como "o ato pelo qual o juiz põe termo ao processo, decidindo ou não o mérito da causa, e com a nova redação passa a ser "o ato do juiz que implica alguma das situações previstas nos arts. 267 e 269 desta Lei” (§1으, art. 162).

Note-se, pois, que a sentença condenatória não mais porá termo ao processo, que prosseguirá o mesmo processo com a fase de cumprimento do julgado.

O presente estudo fará uma breve análise da Lei no. 11.232/2005, principalmente no tocante as três bases, da qual todas as alterações são decorrentes, são elas:

a) liquidação de sentença como procedimento incidental e, não, ação incidental;

b) efetivação da sentença condenatória por quantia certa como etapa final do processo de conhecimento, dispensando a instauração de processo autônomo de execução;

c) extinção dos embargos do executado, devendo toda impugnação ser veiculada por mero incidente.

31 Exceto nos casos da sentença penal condenatória, da sentença estrangeira homologada e da sentença arbitral.

32 Reforma introduzida pela Lei no $10.444 / 2002$. 


\title{
5.1 Da liquidação de sentença
}

A liquidação de sentença sofre modificações, passando ao Titulo VIII, do Livro I, Capítulo IX, denominado "Da Liquidação de Sentença", e se caracteriza como procedimento incidental, e não como antes uma ação incidental. Como conseqüência, o recurso cabível da decisão que fixa o quantum debeatur passa a ser o agravo de instrumento ${ }^{33}$, e não mais a apelação.

Ademais, da redação do $\S 2 \circ$, do artigo 475-A, extrai-se que é possível a liquidação na pendência de recurso, independentemente dos efeitos em que ele seja recebido. Entretanto, como por força do recurso os autos sobem ao tribunal a liquidação provisória deve ser procedida em autos apartados, no juízo de origem, competindo ao liquidante instruir o pedido com as peças processuais pertinente.

\subsection{Do cumprimento da sentença}

No Título VIII, do Livro I, do Código de Processo Civil foi inserido o Capítulo X - "Do Cumprimento da Sentença", e é composto dos artigos 475-I a 475-R.

O artigo 475-J, assim dispõe:

\begin{abstract}
Caso o devedor, condenado ao pagamento de quantia certa ou já fixada em liquidação, não o efetue no prazo de 15 (quinze) dias, o montante da condenação será acrescido de multa no percentual de $10 \%$ (dez por cento) e, a requerimento do credor e observado o disposto no art. 614, inciso II, desta Lei, expedir-se-á mandado de penhora e avaliação.
\end{abstract}

Através deste artigo, concretiza-se a nova sistemática, ficando dotada a sentença de procedência, nos casos de prestação de quantia líquida, não só de eficácia 'condenatória' como também de eficácia 'executiva'34.

Põe-se fim a dicotomia até então existente entre processo de conhecimento e de execução, dando lugar ao que a doutrina denominou de "processo sincrético"35, com a integração das atividades cognitivas e executivas.

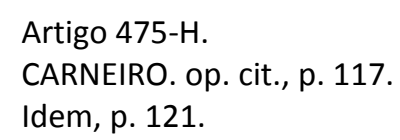


Deste modo, a execução passa a ser apenas uma nova fase do processo de conhecimento, sem a necessidade de instauração de um processo autônomo.

Agora, após a sentença condenatória por quantia líquida - ou após liquidação da sentença - o devedor terá o prazo de quinze dias para cumprir voluntariamente sua obrigação de pagar. Note-se que o artigo não indica a partir de quando começa a fluir o prazo. Athos Gusmão Carneiro ${ }^{36}$ leciona que "tal prazo passa automaticamente a fluir da data em que a sentença (ou o acórdão, CPC art. 512) se torne exeqüível, quer por haver transitado em julgado, quer porque interposto recurso sem efeito suspensivo."

Se o devedor não paga desde logo é expedido mandado de penhora e de avaliação, a requerimento do credor.

J. E. Carreira Alvim e Luciana Gontijo Carreira Alvim Cabral ${ }^{37}$ asseveram que a norma constante do artigo 475-J é uma novidade introduzida pela reforma, sem precedentes na legislação processual. Em comentário ao dispositivo em análise ressaltam que:

Essa regra se fazia necessária, pois, no Brasil, resistir à execução sempre foi um bom negócio para o devedor, que proscratinava o pagamento do débito, obtendo vantagens com a sua própria torpeza, na medida em que os resultados das aplicações financeiras desse dinheiro - com o qual deveria liquidar seu débito ganhava de longe dos reajustes determinados pela Lei 6.899/81, com a aplicação da correção monetária nos débitos resultantes de decisão (sentença) judicial.

\subsection{Da impugnação}

Os embargos do executado também foram alterados, sendo que com a nova redação do artigo qualquer objeção do réu deve ser veiculada mediante mero incidente de impugnação ${ }^{38}$, no prazo de 15 dias.

Ressalta-se, que em regra a 'impugnação' não possui efeito suspensivo, podendo, entretanto, ser atribuído pelo juiz referido efeito quando relevantes seus fundamentos e o prosseguimento da execução seja manifestamente suscetível de causar ao executado grave dano de difícil ou incerta reparação ${ }^{39}$.

\footnotetext{
36 Idem, p. 118.

37 ALVIM, J. E. Carreira; CABRAL, Luciana Gontijo Carreira Alvim. Cumprimento da Sentença: comentários à nova execução de sentença e outras alterações introduzidas no Código de Processo Civil (Lei 11.232/05). Curitiba: Juruá Editora, 2006, p. 65.

38 Art. 475-J, §1ㅇ.

39 Art. 475-M.
} 
Note-se que, ainda quando atribuído efeito suspensivo à impugnação, o exeqüente poderá requerer o prosseguimento da execução, desde que prestada caução suficiente e idônea, a ser arbitrada pelo juiz e prestada nos próprios autos ${ }^{40}$.

Dispôs também que, se deferido efeito suspensivo a impugnação será instruída e decidida nos próprios autos, e, caso contrário, em autos apartados.

Da decisão que resolver a impugnação será oponível agravo de instrumento, salvo quando importar extinção da execução, caso em que caberá apelação ${ }^{41}$.

\section{Conclusão}

Diante da análise realizada no presente estudo, verifica-se a importância e a necessidade premente das mudanças voltadas a modernizar os mecanismos de acesso à prestação jurisdicional justa.

A Lei no. 11.232/2005, tem por finalidade enfrentar um dos pontos cruciais da atualidade - o tempo de duração da lide - tornando mais célere o processo, com a efetivação da sentença condenatória como etapa final do processo de conhecimento e não mais como um processo autônomo de execução.

Busca-se, portanto, a prestação célere e efetiva da tutela jurisdicional, de forma a implementar o acesso à justiça em sua concepção mais abrangente.

Assim, nas palavras de Athos Gusmão Carneiro42, "Aonde vamos? Não se esperem milagres, pois o processo está inserido em uma realidade social em vários aspectos lamentável. Mas necessitamos melhorar nossos procedimentos processuais, depositando esperanças no futuro."

\section{Referências}

ALVIM, J. E. Carreira; CABRAL, Luciana Gontijo Carreira Alvim. Cumprimento da Sentença: comentários à nova execução de sentença e outras alterações introduzidas no Código de Processo Civil (Lei 11.232/05). Curitiba: Juruá Editora, 2006.

ALVIM, J. E. Carreira, Justiça: acesso e decesso. Jus Navigandi, Teresina, v. 7, n. 65, maio 2003. Disponível em: <http://jus2.uol.com.br/doutrina/texto. asp?id=4078>.

\footnotetext{
40 Art. 475-M, §1ㅇ.
} 
ARAÚJO, José Henrique Mouta. O cumprimento da sentença e a 3ํa etapa da reforma processual - Primeiras impressões. Repro, 123, Ano 30, Maio/2005.

BRUSCATO, Wilges. Efetividade do Processo de Execução.. São Paulo: Revista dos Tribunais Repro 129, ano 30, nov./2005.

CÂMARA, Alexandre Freitas. O acesso à justiça no plano dos direitos humanos. In: QUEIROZ, Raphael Augusto Sofiati de (Org.). Acesso à Justiça. Rio de Janeiro: Lúmen Júris.

. O Contempt of Court Brasileiro como Mecanismo de Acesso à Ordem Jurídica Justa.

In: QUEIROZ, Raphael Augusto Sofiati de (Org.). Acesso à Justiça. Rio de Janeiro: Lúmen Júris.

. Lições de Direito Processual Civil. 8. ed. Rio de Janeiro: Lúmen Júris, 2004. v. 2.

CAPPELLETTI, Mauro; GARTH Bryant. Acesso à Justiça. Trad. Ellen Gracie Northfleet. Porto Alegre: Sergio Antonio Fabris, 1988.

CARNEIRO, Athos Gusmão. Nova Execução. Aonde vamos? Vamos melhorar. São Paulo: Revista dos Tribunais - Repro 123, Ano 30, Maio/2005.

DINAMARCO, Cândido Rangel. Instituições de direito processual civil. 5. ed, São Paulo: Malheiros, 2005. v. 1.

GRECO, Leonardo. A execução e a efetividade do processo. São Paulo: Revista dos Tribunais Repro 94, Ano 24, Abril/Junho de 1999.

GRINOVER, Ada Pellegrini. O Processo em evolução. Acesso a Justiça e o Código de Defesa do Consumidor. 2. ed. Rio de Janeiro: Forense Universitária, 1998.

MARTINEZ, Maria Beatriz. O sistema de execução e as reformas do código de processo civil. São Paulo: Revista dos Tribunais - Repro 128, Ano 30, outubro/2005.

RODRIGUES, Horácio Wanderley. Acesso à Justiça no Direito Processual Brasileiro. São Paulo: Acadêmica, 1994.

SOARES, Fabio Costa Acesso do Hipossuficiente à Justiça. A Defensoria Pública e a Tutela dos Interesses Coletivos Lato Sensu dos Necessitados.

THEODORO JUNIOR, Humberto. Celeridade e efetividade da prestação jurisdicional. Insuficiência da reforma das leis processuais. São Paulo: Revista dos Tribunais - Repro 125, Ano 30, Julho/2005. 
WATANABE, Kazuo. Acesso à justiça e sociedade moderna. In: GRINOVER, Ada Pellegrini; DINAMARCO, Cândido Rnangel; WATANABE, Kazuo (Coord.). Participação e processo. São Paulo: Revista dos Tribunais, 1988. 